\title{
Global Health, Equity, and Primary Care
}

\author{
Barbara Starfield, $M D, M P H$
}

Global health provides a special challenge for primary care and general practice, which will become increasingly important in the future as the prevalence of multimorbidity increases with increasing likelihood of survival from acute manifestations of illness, as populations age, and as costs of care increase with increasing availability of technologic interventions. World organizations of primary care physicians need to take up the challenge before it becomes a crisis. (J Am Board Fam Med 2007;20:511-513.)

Interest in the health of other countries is not a new phenomenon. Late in the 19th century, Lord Chamberlain ${ }^{1}$ made clear his view that global health meant "making the tropics safe for white men." In the 21 st century, globalization is providing new imperatives largely because its effects on health are so pronounced, ${ }^{2}$ occurring directly by means of increasing exposures to harmful social and environmental influences and indirectly through influences on health, economic, social, and health services. ${ }^{3}$ Although definitions may vary depending on the particular interests of "global health practitioners," the definition provided by the US Institute of Medicine ${ }^{4}$ provides a useful departure: "global health comprises health problems, issues, and concerns that transcend national boundaries, may be influenced by encounters or experiences in other countries, and are best addressed by cooperative efforts and solutions."

Despite common wisdom about the importance of commonly identified national characteristics, variability in health at any given level of country wealth or health professional supply is enormous ${ }^{5-7}$ providing evidence that differences in health cannot be a direct influence of these characteristics. Might there be a more consistent correlate?

This article was externally peer reviewed.

Submitted 25 July 2007; revised 6 August 2007; accepted 7 August 2007.

From Johns Hopkins University and Medical Institutions, Baltimore, MD.

Funding: none.

Conflict of interest: none declared.

Corresponding author: Barbara Starfield, Johns Hopkins University and Medical Institutions, 624 North Broadway, Room 452, Baltimore, MD 21205 (E-mail: bstarfie@jhsph.edu).
The common focus of 20th century health systems on early identification and management of specific diseases was a by-product of the quest for single etiologies for clinical manifestations, fostered by epidemiologic evidence of environmental clusters of illnesses and the identification of disease-producing "germs." The 21st century era promises to be the era of pervasive effects of globalization, with interacting influences on health, increasing threats to equity in health, multiple cooccurring illnesses ("multimorbidity"), and increasing potential for adverse effects resulting from drug interactions, unnecessary interventions, and errors in providing services.

All these new challenges demand new approaches to organizing services: the disease-by-disease orientation is becoming increasingly dysfunctional. It must be replaced by a focus on people and populations with their unique combinations of illnesses and types of illnesses rather than specific diseases. Clustering of vulnerability, especially in deprived population groups, is associated with nondisease-specific symptoms and syndromes resulting from adverse social biological and environmental impacts. Multimorbidity is demanding not "chronic disease" management but, rather, a chronic care model in which person-focused primary care is the key element. The environment's impact on health and the effects of medical care itself are making it imperative to design services around the principle of rapid access to person-focused, comprehensive, and coordinated services provided over time to achieve early recognition and management for the multiplicity of conditions likely to be long-standing and eventually life-threatening. Known as "primary health care," such services are increasingly essential in meeting the health needs of all populations. ${ }^{8,9}$ 
Barriers to the achievement of these goals may be thwarted by several characteristics of current health systems, particularly in some advanced industrialized nations with powerful hospital and specialist influences, the disease-oriented focus of major donors, and the lack of appreciation of the potential of primary care to foster effective and equitable health services at relatively low costs. ${ }^{10}$ The imperative to maximize corporate market share and profit prevents societal action directed at equity goals ("reductions in disparities"). ${ }^{11}$

Family medicine, acting on a global level, could play a major role in preparing for the new demands on health systems and services. A critical role is to develop a strong evidence base concerning the distribution of health problems, the way in which they present in community practice, and how they are modified by various types of interventions. Diseaseoriented specialists cannot be the experts in how health problems are manifested in the community; the patients they see are not representative of the universe of patients with similar manifestations of problems. ${ }^{12}$ Because of their training and experiences, they overestimate the likelihood of serious illness and therefore intervene excessively and unnecessarily in people who do not need their services. In their quest to find a specific disease and course of management, they are unable to deal with multimorbidity and the dangers of drug interactions for various syndromes and diseases. ${ }^{13}$

World family medicine must assume responsibility for changing outmoded hospital-based training. ${ }^{14}$ The new imperative is to keep people away from hospitals by early, ongoing problem recognition and management in the community. Most diagnostic challenges, except for rare manifestations, are in the community, which is the most appropriate site for the training of health practitioners to provide ongoing care over time.

Another imperative for world family medicine is to come to grips with defining an appropriate scope for primary care practice. Countries, and areas within countries, vary widely in what problems are considered primary care problems. ${ }^{15,16}$ Countries with a broader range of services within primary care achieve it by training family physicians with a broader range of skills. In countries such as the United States (where primary care general internist and general pediatrician primary care physicians are trained relatively narrowly in a disease-focused model), achieving greater comprehensiveness will require either an expansion of training experiences or the incorporation of other types of professionals into primary care teams. The new focus on "general practitioners with specialty interests" further threatens to reduce the breadth of primary care practice through its focus on specific types of problems with a loss of competence in dealing with the challenges of primary care problems. ${ }^{17}$ Greater comprehensiveness (ie, breadth) of primary care practice, including services such as minor surgery, is associated with higher quality of primary care in general and better outcomes of care with lower costs. ${ }^{10}$ It also reduces the likelihood of excessively costly, unnecessary, and potentially dangerous specialist referrals. ${ }^{10,13} \mathrm{~A}$ wider range of focus allows health practitioners to better integrate all aspects of patient care rather than concentrating primarily on specific diagnoses and types of diagnoses. Although the range of services that are appropriately provided will depend on the needs of the population served, the frequency of particular types of diagnoses should determine which problems are in the province of primary care and which need referral to specialists for advice, guidance, and limited longterm management. Even though the range of services to be covered in primary care varies from area to area (as does the availability of primary care practitioners), principles for making decisions about the appropriate range of services in primary care need development by family physicians throughout the world.

Global health provides a special challenge for primary care and general practice, which will become increasingly important in the future as the prevalence of multimorbidity increases with increasing likelihood of survival from acute manifestations of illness, as populations age, and as costs of care increase with increasing availability of technologic interventions. World organizations need to become stronger advocates for primary care if the crisis in health system capacity is to be avoided.

\section{References}

1. Ming HT. Doctors in the east: when west meets east. Malaysia: Pelanduk Publications; 2001.

2. Gostin LO. Why rich countries should care about the world's least healthy people. JAMA 2007;298(1): 89-92.

3. Woodward D, Drager N, Beaglehole R, Lipson D. Globalization and health: a framework for analysis and action. Bull World Health Organ 2001;79(9): 875-81. 
4. Institute of Medicine Board on International Health. America's vital interest in global health: protecting our people, enhancing our economy, and advancing our international interests. Washington, DC: National Academy Press; 1997.

5. Chen L, Evans T, Anand S, et al. Human resources for health: overcoming the crisis. Lancet 2004;364(9449):1984-90.

6. Karolinska Institute. Global health chart, 2004 [cited 2007 July 9]. Available from: www.whc.ki.se/index. php.

7. Economist Intelligence Unit. Healthcare international. 4th quarter 1999. London (UK): Economist Intelligence Unit; 1999.

8. Samarasekera U. Margaret Chan's vision for WHO. Lancet 2007;369(9577):1915-6.

9. American Academy of Family Physicians. Joint principles of the patient-centered medical home, March 2007 [cited 2 Aug 2007]. Available from: http:www. medicalhomeinfo.org/Joint\%20Statement.pdf.

10. Starfield B, Shi L, Macinko J. Contribution of primary care to health systems and health. Milbank Q 2005;83(3):457-502.

11. Gilson L, Doherty J, Loewenson R, Francis V. Challenging inequity through health systems. Final report, Knowledge Network on Health Systems, June 2007. WHO Commission on the Social Determi- nants of Health. Johanesburg, South Africa: Centre for Health Policy, University of Witwatersand; 2007.

12. Sox HC. Decision-making: a comparison of referral practice and primary care. J Fam Pract 1996;42(2): 155-60.

13. Starfield B, Shi L, Grover A, Macinko J. The effects of specialist supply on populations' health: assessing the evidence. Health Aff 2005; W5:97-107. Available from: http://content.healthaffairs.org/cgi/ reprint/hlthaff.w5.97v1.

14. Gibbon W. Medical schools for the health-care needs of the 21st century. Lancet 2007;369(9580): 2211-3.

15. Bindman $\mathrm{AB}$, Forrest $\mathrm{CB}$, Britt $\mathrm{H}$, Crampton $\mathrm{P}$, Majeed A. Diagnostic scope of and exposure to primary care physicians in Australia, New Zealand, and the United States: cross sectional analysis of results from three national surveys. BMJ 2007;334(7606): 1261-6.

16. Starfield B, Shi L. Policy relevant determinants of health: an international perspective. Health Policy 2002;60(3):201-18.

17. Starfield B, Gervas J. Comprehensiveness v special interests: Family medicine should encourage its clinicians to subspecialize: Negative. In: Kennealy T, Buetow S, editors. Ideological debates in family medicine. New York (NY): Nova Publishing; 2007. 